\title{
PROCEEDINGS \\ OF THE
}

\section{EDINBURGH MATHEMATICAL SOCIETY}

EDITED BY
T. S. BLYTH
C. M. CAMPBELL
T. A. GILLESPIE
J. HOWIE
C. J. SHADDOCK
B. D. SLEEMAN

CONSULTING EDITORS
Sir MICHAEL ATIYAH, F.R.S.
A. M. MACBEATH
G. BROWN
J. B. MCLEOD
D. L. COLTON
C. St. J. A. NASH-WILLIAMS
P. A. FILLMORE
D. J. S. ROBINSON
C. M. GORDON
C. A. STUART

VOLUME 31 (SERIES II)

1988 
COPYRIGHT $\mathcal{C} 1988$ THE EDINBURGH MATHEMATICAL SOCIETY

Printed in Great Britain by Bell and Bain Ltd., Glasgow 


\section{CONTENTS}

ELSA ABBENA AND SERgIo GARBIERo Almost Hermitian homogeneous structures

S. A. ADELEKE Embeddings of infinite permutation groups in sharp, highly transitive, and homogeneous groups

T. ANDERSON, K. KAARLI AND R. WIEGANDT On left strong radicals of near-rings

J. ARIAS DE REYNA Hausdorff dimension of Banach spaces

D. D. BAINOV, M. A. HEKIMOVA AND V. M. VEliov Boundary value problem for a singularly perturbed system of linear differential equations with impulses

D. D. BAINOV, SEe P. S. SIMEONOV

U. BALAKRISHNAN A series for $\zeta(s)$

OSCAR BLASCO Positive $p$-summing operators, vector measures and tensor products

D. K. Blevins, K. D. MAGILl, JR., P. R. MISRA, J. C. PARNAMI AND U. B. TEWARI More on automorphism groups of laminated near-rings

BOOK REVIEWS

KENNETH A. BROWN AND THIERRY LEVASSEUR Cohomology of induced modules in rings of differential operators

PATRICK J. BROWNE AND HAMLET ISAEV Symmetric multiparameter problems and deficiency index theory

PATRICK J. BROWNE AND B. D. SLEEMAN Inverse multiparameter eigenvalue problems for matrices III

ANTHONY CARBERY Covering lemmas revisited

SÔNIA P. COELho AND C. POLCINO MILIES A note on central idempotents in group rings II

DAvid Colton Dense sets and far field patterns for acoustic waves in an inhomogeneous medium

MARTYN R. DIXON Fitting classes of CC-groups

DAVID EASDOWN Biorder-preserving coextensions of fundamental semigroups

ALBERTO ESPUELAS A nonabelian Frobenius-Wielandt complement

SERGIO GARBIERO, SEe ELSA ABBENA

J. A. GERHARD AND MARIO PETRICH Certain characterizations of varieties of bands

K. R. GOODEARL AND D. A. JORDAN Localizations of essential extensions

T. N. T. GOODMAN AND S. L. LEE Convolution operators with trigonometric spline kernels 
K. P. HADELER Hyperbolic travelling fronts

D. J. HALLENBECK AND T. H. MAcGREGor Radial growth and variation of bounded analytic functions

M. A. HEKIMOVA, See D. D. BAINOV

HERMANN HEINEKEN Groups with restriction on their infinite subnormal subgroups

HAMLET ISAEV, SEe PATRICK J. BROWNE

LUCAS JÓDAR An algorithm for solving generalized algebraic Lyapunov equations in Hilbert space, applications to boundary value problems

K. G. JOHNSTON Lattice isomorphisms of modular inverse semigroups

D. A. JORDAN, SEe K. R. GOODEARL

K. KAARLI, SEe T. ANDERSON

S. L. LEE, SEe T. N. T. GOODMAN

SIEGFRIED H. LEHNIGK Maximum-likelihood estimation of the parameters of a four-parameter class of probability distributions

THIERRY LEVASSEUR, SEe KENNETH A. BROWN

CARTER G. LYONS AND GARY L. PETERSON Local endomorphism near-rings

D. F. McGHeE AND M. H. SALlam Simple eigenvalues and bifurcation for a multiparameter problem

T. H. MACGREGOR, SEe D. J. HALLENBECK

K. D. MAGILL, JR., See D. K. BLEVINS

C. POLCINO MILIES, SEe SÓNIA P. COELHO

KENNETH G. MILLER Microlocal regularity on step two nilpotent Lie groups

P. R. MISRA, SEe D. K. BLEVINS

S. E. А. монаммеD Unstable invariant distributions for a class of stochastic delay equations

G. J. MURPHY Sums of Laurent and bilateral Hankel operators

JUAN J. NIETO Aronszajn's theorem for some nonlinear Dirichlet problems with unbounded nonlinearities

L. O'CARROLL Torsion-free pre-images of modules of finite length

M. M. PARMENTER On the automorphisms of the group ring of a finitely generated free abelian group

J. C. PARNAMI, SEe D. K. BLEVINS 
GARY L. PETERSON, SEe CARTER G. LYONS

MARIO PETRICH, SEe J. A. GERHARD

massimo a. PiCARdello and wolfgang woess Harmonic functions and ends of graphs

IAIN RAEBURN On crossed products and Takai duality

GERHARD ROSENBERGER Minimal generating systems of a subgroup of $S L(2, \mathbb{C})$

B. P. RYNNE Multiparameter spectral theory of singular differential operators

B. P. RYNNE Multiparameter spectral theory and Taylor's joint spectrum in Hilbert space

M. H. SALLAM, see D. F. McGHEE

S. I. SENASHOV AND A. M. VINOGRADOV Symmetries and conservation laws of 2dimensional ideal plasticity

P. S. SIMEONOV AND D. D. BAINOV Asymptotic equivalence of a linear and nonlinear system with impulse effect

P. S. SIMEONOV AND D. D. BAINOV Differentiability of solutions of systems with impulse effect with respect to initial data and parameter

B. D. SLEEMAN, SEe PATRICK J. BROWNE

U. B. TEWARI, SEe D. K. BLEVINS

M. J. TOMKINSON Infinite quasi-injective groups

JINGCHENG TONG A theorem on approximation of irrational numbers by simple continued fractions

ROBERT $W$. VAN DER WAALL On the determination of the ramification index in Clifford's theorem

V. M. VELIOV, SEe D. D. BAINOV

A. M. VINOGRADOV, SEe S. I. SENASHOV

N. A. WATSON Boundary behaviour of harmonic functions and solutions of parabolic systems

R. WIEGANDT, SEe T. ANDERSON

WOLFGANG WOESS, see MASSIMO A. PICARDELlo 


\section{THE EDINBURGH MATHEMATICAL SOCIETY}

The Edinburgh Mathematical Society was instituted in 1883 for "the promotion and extension of Mathematical Science, Pure and Applied".

Nominations for Ordinary Membership are received at any one Ordinary Meeting and voted upon at the next. Members receive notices of all meetings and may subscribe to the Proceedings at a reduced rate. Further information about membership can be obtained from the Secretary.

The Society's Proceedings, containing papers embodying the results of research that is original in matter or manner, are published in parts. Three parts complete a volume. One volume is issued each year. Series I comprised forty-four volumes published from 1884 to 1926. Series II commenced in 1927.

Papers to be considered for publication should be sent to the Secretary. Manuscripts ( 2 copies) should be typewritten on A4 paper with double spacing and generous margins. The style and arrangement should conform to current practice in the Proceedings. References, including titles of papers, should be given in the form adopted by Mathematical Reviews, footnotes being avoided if possible. Figures should be separated from the text and lettered, ready for photographic reduction; their intended location should be clearly indicated. Manuscripts which are not suitable for submission to the printer will not be accepted. Authors are advised to retain a copy of any material submitted, as the Society cannot accept responsibility for any loss.

A proof is supplied once. Authors are particularly requested to correct and return the proof promptly. Excessive corrections may be charged to authors. Fifty free offprints, and additional copies at cost, will be supplied if ordered on a form returned with the proof.

The Proceedings are published at the price of $£ 45.00$ ( $\$ 100)$ for a volume of three parts.

Enquiries regarding purchase of back numbers should be addressed to

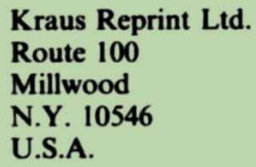

for volumes of Series I and up to Volume 14 of Series II, and to the publishers

Scottish Academic Press Ltd.

33 Montgomery Street

Edinburgh EH7 5JX

for subsequent issues.

The Society's address is

The Edinburgh Mathematical Society

James Clerk Maxwell Building

The King's Buildings

Edinburgh EH9 3JZ

Communications concerning the Library should be addressed to the Librarian.

All other correspondence should be addressed to the Secretary.

COPYRIGHT (C) 1988 THE EDINBURGH MATHEMATICAL SOCIETY

Printed in Great Britain by Bell and Bain Ltd., Glasgow 


\section{TEXTS IN MATHEMATICS AT BARGAIN PRICES}

The Spectral Theory of Periodic Differential Equations

By M.S.P. Fastham

The book deals mainly with second-order differential equations in one or more dimensions and covers the hasic Floquet theory. the zeros and oscillatory properties of solutions. etc. the relationship of the theory to the general theory of differential operators in Hilbert space. and the methods available which enable a mathematical theory of the periodic Schrödinger equation to be huilt up.

First published 1973

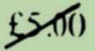

Price now $£ 1.50$

\section{Analytical Methods of Optimization}

By ID.F. Lawden

A presentation of the classical theory of the calculus of variations in a form which is most appropriate for application to modern problems of optimizing the behaviour of engineering systems. The emphasis is on methods and principles and these are illustrated by worked problems and sets of exercises.

First puhlished 1975

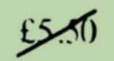

Price now $£ 1.50$

\section{Theory and Application of the Boltzmann Equation}

By Carlo Cercignani

The Boltzmann eyuation forms the basis for the kinetic theory of gases and has proved fruitful for a study of the classical gases Ludwig Boltzmann had in mind and also, properly generalised, of electron transport in nuclear physics, phonon transport in superfluids, and radiative transport in planetary and stellar atmosphere. The text of Carlo ('ercignani's book presents a unified approach to the problems arising in these fields.

First published 1975

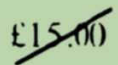

Price now 14.00

\section{Introduction to Numerical Analysis}

By $\mathbf{F}$. Stummel and $\mathrm{K}$. Hainer.

Edited by Professor W.N. Fiveritt

A clear. concentrated and well-arranged introduction to the methods and processes of numerical analysis. Many examples are given to illustrate the processes and to serve as problems for a practical mathematics course in computing.

First published 1980

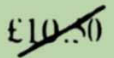

Price now $£ 3 .(0)$

NB: The previous selling prices are as shown in the current catalogue and not necessarily those shown on the hooks themselves. There is no charge for postage. 